Am J Prev Med. 2016 July ; 51(1): 129-138. doi:10.1016/j.amepre.2016.01.017.

\title{
Economic Evaluation of School-based Health Centers: A Community Guide Systematic Review
}

\author{
Tao Ran, PhD, Sajal Chattopadhyay, PhD, Robert A. Hahn, PhD, and the Community \\ Preventive Services Task Force \\ From the Community Guide Branch, Division of Public Health Information Dissemination, Center \\ for Surveillance, Epidemiology, and Laboratory Services, CDC, Atlanta, Georgia
}

\section{Abstract}

Context: A recent Community Guide systematic review of the effectiveness of school-based health centers (SBHCs) showed that SBHCs improved educational and health outcomes. The objective of the present review is to evaluate the economic cost and benefit of SBHCs.

Evidence acquisition: Using economic systematic review methods developed for the Guide to Community Preventive Services, 6,958 papers were identified for the search period January 1985 to September 2014. After two rounds of screening, 22 studies were included in this review. Among them, 15 studies reported on cost and 10 on benefit.

Evidence synthesis: Analyses were conducted in 2014. Intervention cost had two main components: start-up cost and operation cost. All but two of the cost studies reported operation cost only, which ranged from $\$ 16,300$ to $\$ 659,684$ yearly per SBHC. Benefits included healthcare cost averted, productivity and other loss averted. From the societal perspective, total annual benefit per SBHC ranged from $\$ 15,028$ to $\$ 912,878$. From the healthcare payers' perspective, particularly Medicaid, SBHCs led to net savings ranging from $\$ 30$ to $\$ 969$ per visit, and $\$ 46$ to $\$ 1,166$ per person. Additionally, two benefit studies used regression analysis to show that Medicaid cost and hospitalization cost decreased with the presence of SBHCs. Finally, results from two cost-benefit studies showed that the societal benefit per SBHC exceeded intervention cost, with the benefit-cost ratio ranging from 1.38 to 3.05 .

Conclusions: The economic benefit of SBHCs exceeded the intervention operation cost. Further, SBHCs were related to net savings to Medicaid.

\section{Context}

School-based health centers (SBHCs) provide health services to students at centers in K-12 schools or at off-site health facilities linked to schools. Most SBHCs are targeted to students in low-income communities. Services provided by SBHCs in the U.S. include comprehensive physical and mental health assessments (97\%), vision, hearing, and other screening services (93\%), and immunizations (85\%). In addition, a majority of SBHCs

Address correspondence and reprint requests to: Tao Ran, Community Guide Branch, Centers for Disease Control and Prevention, 1600 Clifton Road, Mailstop E69, Atlanta, GA 30329.xgy2@cdc.gov.

The names and affiliations of the Task Force members are at http://www.thecommunityguide.org/about/task-force-members.html. 
provide pregnancy testing (81\%), contraceptive counseling (70\%), and follow-up services for contraceptive users $(59 \%){ }^{1}$

Conceptually, SBHCs can improve children's and adolescents' health status, and reduce health care disparities across groups. SBHCs can meet the students' physical health and mental health needs, which may not be addressed by a complex and fragmented healthcare system. ${ }^{2}$ SBHCs provide students easier access to health services; this reduces time missed at school and helps parents to avoid losing work time and spending extra to transport their children to and from healthcare facilities. In addition, SBHCs provide services to students from different racial and socio-economic backgrounds, particularly underinsured/uninsured individuals who face challenges in accessing primary health care.

In October 2014, the Community Preventive Services Task Force recommended the implementation and maintenance of school-based health centers (SBHCs) in low-income communities, based on sufficient evidence of effectiveness in improving educational and health outcomes. Improved educational outcomes include school performance, grade promotion, and high school completion. Improved health outcomes include the delivery of vaccinations and other recommended preventive services, asthma morbidity, emergency department (ED) and hospital admissions, contraceptive use among females, prenatal care and birth weight, and other health risk behaviors (http://www.thecommunityguide.org/ healthequity/education/schoolbasedhealthcenters.html).

Because SBHCs are effective in addressing the above-mentioned issues, the economic benefits of adopting SBHCs can be substantial. First, there can be considerable net savings to healthcare payers and society due to reductions in ED use. The overuse of EDs, either for non-emergency purposes or as a result of delayed treatment, can place a huge burden on society. In particular, Medicaid patients tend to use EDs frequently because of the difficulty in seeing regular healthcare providers. ${ }^{4}$ Second, SBHCs can provide timely and effective care to students with asthma (asthma prevalence for children under age 18 was $9.5 \% 5$ in 2010) reducing costs associated with asthma-associated ED use and hospitalization. Third, SBHCs can reduce missed school time, and avert productivity losses and transportation expenses for students and their parents. Fourth, reproductive services provided by SBHCs can provide both short- and long-term benefits to students, healthcare payers, and society by reducing unintended teen pregnancy.

Given the effectiveness and potential benefits of SBHCs, systematic assessment of their cost and benefit is important to evaluate the feasibility of implementing this intervention. The objective of this study was to conduct an economic evaluation of SBHCs based on a systematic review.

\section{Evidence Acquisition}

For the purposes of this review SBHCs were defined as follows:

School-based health centers (SBHCs) provide health services to students preK-12 and may be offered on-site (i.e., school-based centers) or off-site (i.e., school-linked centers). SBHCs 
are often established in schools that serve predominantly low-income communities and have the following characteristics:

- $\quad$ SBHCs must provide primary health care and may also include mental health care, social services, dentistry, and health education.

- $\quad$ Primary care services may be provided by a single clinician, or comprehensive services may be provided by multi-disciplinary teams.

- $\quad$ Services may be available only during some school days or hours, and may also be available in non-school hours.

- $\quad$ Student participation requires parental consent, and services provided for individual students may be limited for specific types of care, such as reproductive or mental health.

- $\quad$ Services may be provided to school staff, student family members, and others within the surrounding community.

- $\quad$ Services are often provided by a medical center or provider independent of the school system.

General methods for Community Guide systematic economic reviews are available at www.thecommunityguide.org/about/economics.html. ${ }^{6}$ The inclusion criteria for this review followed the standard for economic evaluation studies adopted by the Community Guide.

Studies were considered relevant if they met the intervention definition and:

- $\quad$ provided cost or benefit information;

- were primary studies, as either a peer-reviewed paper or report;

- were conducted in high-income countries as defined by the World Bank ${ }^{7}$; and

- were written in English.

Multiple databases were used for the systematic search, including PubMed, EconLit, ERIC, JSTOR, Social Sciences Citation Index (SSCI), databases at the Centre for Reviews \& Dissemination at the University of York, and Google Scholar. The search period was between January 1985 and September 2014. To identify relevant studies, the economic keywords were used in the search strategy (Appendix Table 1, available online), in addition to the effectiveness and subject keywords.

To ensure comparability of the studies, costs and expenditures were adjusted to 2013 dollars using the consumer price index (CPI) from the Bureau of Labor Statistics. ${ }^{8}$ Once the intervention cost and benefit were comparable among studies, major contributors to variations in cost and benefit were identified. When data were available, estimates per SBHC user were calculated by dividing cost or benefit by the total number of SBHC users. Finally, economic evidence was summarized to evaluate the benefit of SBHC with respect to intervention costs. Evidence gaps of the studies were also listed. 


\section{Evidence Synthesis}

\section{Search Results}

A total of 6,958 papers were found in the initial literature search, of which 6,824 were excluded after the first round of screening on abstracts. Another 115 papers were excluded after the second round of screening on main text. This yielded 19 articles from the database search. Three papers were added from the effectiveness review, ${ }^{3}$ which led to 22 included studies ${ }^{1,2,9-28}$ (Figure 1). Details of the included studies are available at www.thecommunityguide.org/***. Analyses were conducted in 2014.

\section{Characteristics of Studies}

Seventeen $1,2,10,12-18,20-22,24-26,28$ of the 22 papers were peer-reviewed journal articles. The non-journal articles $9,11,19,23,27$ were mainly reports on either the cost or benefit of the intervention. Geographically, all studies were from the U.S., with five ${ }^{1,2,11,21,22}$ from the Northwest, six ${ }^{16,19,23,25-27}$ from the Northeast, two ${ }^{17,18}$ from the Midwest, two ${ }^{9,10}$ from the Southeast, and seven ${ }^{12-15,20,24,28}$ covering the whole U.S. Fifteen ${ }^{1,11-16,18-22,24,26,28}$ of the 22 papers provided cost information, and ten ${ }^{2,9-11,17-19,23,25,27}$ provided benefit information. Three studies ${ }^{11,18,19}$ provided both the cost and benefit information.

\section{Perspectives of the studies}

On the benefit side, different perspectives were taken by the authors. The majority of the papers took either societal or Medicaid (healthcare payers') perspective, with the remaining taking either patients' (including patients' parents) or other perspectives. The societal perspective included all the relevant parties in society, whereas either Medicaid (healthcare payers') or patients' perspective was partial, in that only the benefit of a specific group was considered.

Of the ten benefit studies $2,9-11,17-19,23,25,27$, three ${ }^{11,18,19}$ took societal perspective; four ${ }^{10,17,18,23}$ took Medicaid (healthcare payers') perspective; two ${ }^{9,25}$ took patients' perspective; and another two ${ }^{2,27}$ provided information on savings to taxpayers or other, unidentified parties. One study ${ }^{18}$ examined results from both societal and Medicaid perspectives.

\section{Intervention Cost}

SBHC intervention costs had two main components: start-up cost (one-time, fixed costs) and operation cost (recurring annually). Table 1 provides detailed information on cost estimates from each study.

Only two studies provided estimates of start-up costs. ${ }^{19,22}$ The first study ${ }^{19}$ presented startup cost for the SBHCs in western and central New York State, including the cost of renovating or constructing the school space, the purchase of initial office and medical equipment, as well as staff salaries in the initial implementation phase, and found startup costs to range from $\$ 216,402$ to $\$ 378,704$ per SBHC. The second study ${ }^{22}$ discussed the startup cost of 42 SBHCs in Oregon, and found it ranged from $\$ 41,450$ to $\$ 195,324$ per SBHC. The minimum of the range was based on SBHCs that used renovated space of the school, and the maximum 
of the range was based on SBHCs that built a medical modular unit on campus. Of note, the startup cost components of the Oregon study were similar to those of the New York study.

Fourteen studies provided information on annual SBHC operation costs, including recurring cost of additional medical equipment and services and non-medical costs such as salaries and benefits and utilities. 1,11-16,18,20-22,24,26,28 Five studies used actual operation cost $12,18,21,22,26$, while nine studies $1,11,13-16,20,24,28$ estimated costs from proxies such as operating budget, grant funding, or operating revenues. Operation costs ranged from $\$ 16,322$ to $\$ 659,684$ per SBHC per year. Operation cost per SBHC user (calculated from five studies $11,16,18,21,22$ with complete information) ranged from $\$ 142.79$ to $\$ 1,802.42$.

The major operation cost driver was salaries and benefits, which accounted for $80 \%-90 \%$ of the operation cost. The main causes of variation in operation cost included hours of work of physicians and staff, local cost of living, nationwide versus state study, and data source. For example, Guo et al. ${ }^{18}$ had relatively low operation cost, ranging from $\$ 118,376$ to $\$ 168,700$, because the pediatricians only worked 3 hours per week. Further, operation cost varied among the states. For instance, Schlitt and colleagues $(2008)^{24}$ provided grant funding information for 19 states, ranging from $\$ 16,322$ to $\$ 306,476$.

\section{Intervention Benefit}

For purposes of this review, benefit components were categorized into two groups (benefit components of each study are listed in Appendix Table 2, available online):

- $\quad$ Healthcare cost averted (i.e., averted cost associated with hospitalization, ED, drugs, referrals, private clinic visits, and unintended pregnancy);

- $\quad$ Productivity and other loss averted (i.e., averted cost associated with productivity loss, travel cost, school time, and others such as ambulance use or improved health).

In terms of perspectives, benefit studies from the societal perspective reported treatment cost averted, lost productivity averted, cost of transportation averted, and other relevant benefits. Studies from Medicaid (healthcare payers') perspective reported (or were calculated by the reviewers) per SBHC user or per visit net savings to Medicaid, which were mainly related to treatment cost averted. Studies from patients' (including patients' parents) perspective reported (or were calculated by the reviewers) savings per visit in treatment cost, lost productivity and transportation, and per user savings in raising a child due to unintended pregnancy avoided. The remaining studies reported (or were calculated by the reviewers) savings per visit to taxpayers or other, unidentified parties.

Table 2 gives the details on benefit information from different perspectives. Three studies ${ }^{10,17,18}$ used actual data. Of the three, two studies ${ }^{10,17}$ calculated benefit using difference in differences method, and one ${ }^{18}$ used pre-post study design. The remaining seven studies $2,9,11,19,23,25,27$ estimated benefits based on different assumptions on the effectiveness of SBHC services.

From the societal perspective, total annual benefit per SBHC ranged from $\$ 15,028$ to $\$ 912,878$ (based on three studies ${ }^{11,18,19}$ ). The variation in benefit was mainly related to 
whether the study included major benefit drivers such as savings related to unintended pregnancies averted. Of note, savings related to unintended pregnancy avoided in Brindis 1993 were the avoided "public cost of pregnancies"11, which was the largest contributor (accounting for more than 85\%) to benefit. In comparison, even though Guo 2010 had six components, it did not include benefit from averted ED use or unintended pregnancy. The minimum of the range $(\$ 15,028)$ was the benefit calculated in Horton, ${ }^{19}$ which only included inpatient cost averted from students with asthma.

From the Medicaid (healthcare payers') perspective, SBHCs led to net savings to Medicaid (i.e, the difference between total savings to Medicaid related to SBHCs and the Medicaid spending on SBHC services was positive), ranging from $\$ 30$ to $\$ 969$ per visit (based on three studies ${ }^{17,18,23}$ that provided relevant information), and $\$ 46$ to $\$ 1,166$ per user (based on two studies ${ }^{10,18}$ that provided relevant information). The variation in net Medicaid savings was large because the studies examined different benefit components. Studies with more components appeared to have had higher net savings. Further, studies reporting ED use averted tended to have higher savings. In addition, studies focused on students with asthma tended to have higher net savings.

Additionally, from Medicaid (healthcare payers') perspective, two benefit studies ${ }^{10,17}$ used regression analysis to show that Medicaid cost related to ED use and to hospitalization decreased with the adoption of SBHCs (details are provided in Appendix Table 3, available online).

From patients' (including patients' parents) perspective, SBHC usage was related to per visit savings of $\$ 90$ in Siegel $1987^{25}$, and to savings per user of $\$ 23,592$ in Contraceptive Technology Update report $1985^{9}$. In both studies, the enrolled students received SBHC services for free (per visit cost of $\$ 43.86$ in Siegel was covered by the Division of Public Health; and per user cost of $\$ 345$ in the second study was covered by different funding sources). Siegel concluded that students would save money in using SBHCs instead of private clinics. Contraceptive Technology Update only reported the cost saved from not raising a child due to unintended pregnancy avoided.

Benefit in the remaining two studies ${ }^{2,27}$ were mainly related to ED use. Children's Aid Society 2012 reported $\$ 1,077$ savings per visit to taxpayers. Brindis 1997 reported $\$ 162$ to \$262 savings per visit (perspective unidentified).

\section{Benefit-Cost Ratios}

Table 3 presents benefit-cost ratios from seven schools in two studies. ${ }^{11,18}$ In both studies, societal benefit per SBHC exceeded intervention cost, with the benefit-cost ratio ranging from 1.38:1 to 3.05:1. Even though the two studies were similar in terms of SBHC services and the number of users, the calculations of benefit were different. Guo ${ }^{18}$ calculated benefits in a relatively comprehensive way by including six benefit components, whereas Brindis ${ }^{11}$ only included two major benefit components (ED use and unintended pregnancy). Moreover, economic benefit from unintended pregnancies averted, which included the public cost of children born to teenagers, accounted for over $85 \%$ of the total benefit. 


\section{Summary of Findings}

In summary, there is evidence that the benefit of school-based health centers exceeded cost. In addition, SBHCs are related to net saving to Medicaid.

\section{Discussion}

In conjunction with the findings of the concurrent systematic review on effectiveness ${ }^{3}$, the results of this economic review provide evidence that SBHCs are an effective, and efficient setting for healthcare delivery. Studies identified in this systematic review indicate that with moderate operation cost, SBHCs contribute meaningful economic benefits to society, healthcare payers (especially Medicaid), and patients.

In contrast to the range of educational and health outcomes examined in the effectiveness review, the studies providing economic assessments focused on health and health carerelated outcomes. From the societal perspective, benefit was mainly related to savings from unintended pregnancy and productivity loss averted. From the Medicaid perspective, ED use was the major driver of the economic benefit. In addition, studies focused on SBHC services to students with asthma found that SBHCs provided significant net savings to Medicaid. Finally, SBHCs saved patients (and their parents') expenses associated with pregnancy and with lost work.

\section{Limitations}

From the cost side, only two studies ${ }^{19,22}$ reported start-up cost. This might cause the annual total cost to be underestimated. However, once the one-time start-up cost was amortized, it would be much lower than annual operation cost. Further, only four studies ${ }^{11,16,18,22}$ reported the number of SBHC users, which might cause imprecise estimation of per user cost. Likewise, only two studies ${ }^{16,18}$ provided information on the number of students. In addition, nine studies ${ }^{1,11,13-16,20,24,28}$ used proxies such as operating budget, grant funding, or operating revenues to estimate cost, or simply quoted from other studies. However, the range of the estimated costs were similar to the range of the actual costs in the rest of the cost studies.

From the benefit side, only three studies ${ }^{10,17,18}$ used actual data. The remaining studies estimated benefit based on different assumptions. For instance, Massachusetts SBHC association 2012 report assumed that ED use was reduced by 50\%, an estimate higher than the median decrease of $15.8 \%$ identified in a recent systematic review. ${ }^{3}$ This could lead to overestimate of the benefit. Further, only six studies ${ }^{2,10,17,18,25,27}$ clearly specified the time horizon of benefit. Others were somewhat ambiguous, with one ${ }^{11}$ study's time horizon implied by the context and methodology. This can cause complication in calculating benefit per year. In addition, most of the studies did not clearly specify the perspective(s) taken by the authors. Therefore, the classification of perspectives was conducted by the reviewers based on the results of the studies. Finally, studies ${ }^{9,11}$ including unintended teen pregnancy averted did not specify the subcomponents or time horizon of this estimate, complicating interpretation of the overall benefit. 


\section{Evidence gaps}

More complete and comprehensive reporting of benefit and its components is needed, including clear reporting of the study time horizon. Additional economic assessments are needed to examine the broader range of outcomes considered in the concurrent effectiveness review. ${ }^{3}$ In spite of the effectiveness of SBHCs in improving academic performance, for example, none of the economic studies incorporated these outcomes in their benefit assessments. Economic assessments or models based on longer-term assessments of outcomes might be needed to capture the full range of benefits attributable to SBHC services.

Finally, none of the studies identified in this review provided cost-effectiveness assessments of SBHCs. Future studies should conduct cost-effectiveness analyses, and provide evidence on cost per quality adjusted life-year (QALY) gained. Cost-effectiveness studies of overall SBHCs and focused studies of specific services (such as reproductive health) would be useful to program planners and decision-makers.

\section{Supplementary Material}

Refer to Web version on PubMed Central for supplementary material.

\section{Acknowledgements}

The authors acknowledge the effectiveness review team, including Robert Hahn, Ramona Finnie, John Knopf, and Yinan Peng, as well as Randy Elder, David Hopkins, Verughese Jacob, Kate W. Harris, Krista Cole, and Onnalee Gomez from the Community Guide Branch, CDC, for helpful input in the literature search and the preparation of the review.

The work of Tao Ran, was supported with funds from the Oak Ridge Institute for Scientific Education.

The findings and conclusions in this paper are those of the authors and do not necessarily represent the official position of the CDC.

\section{Appendix}




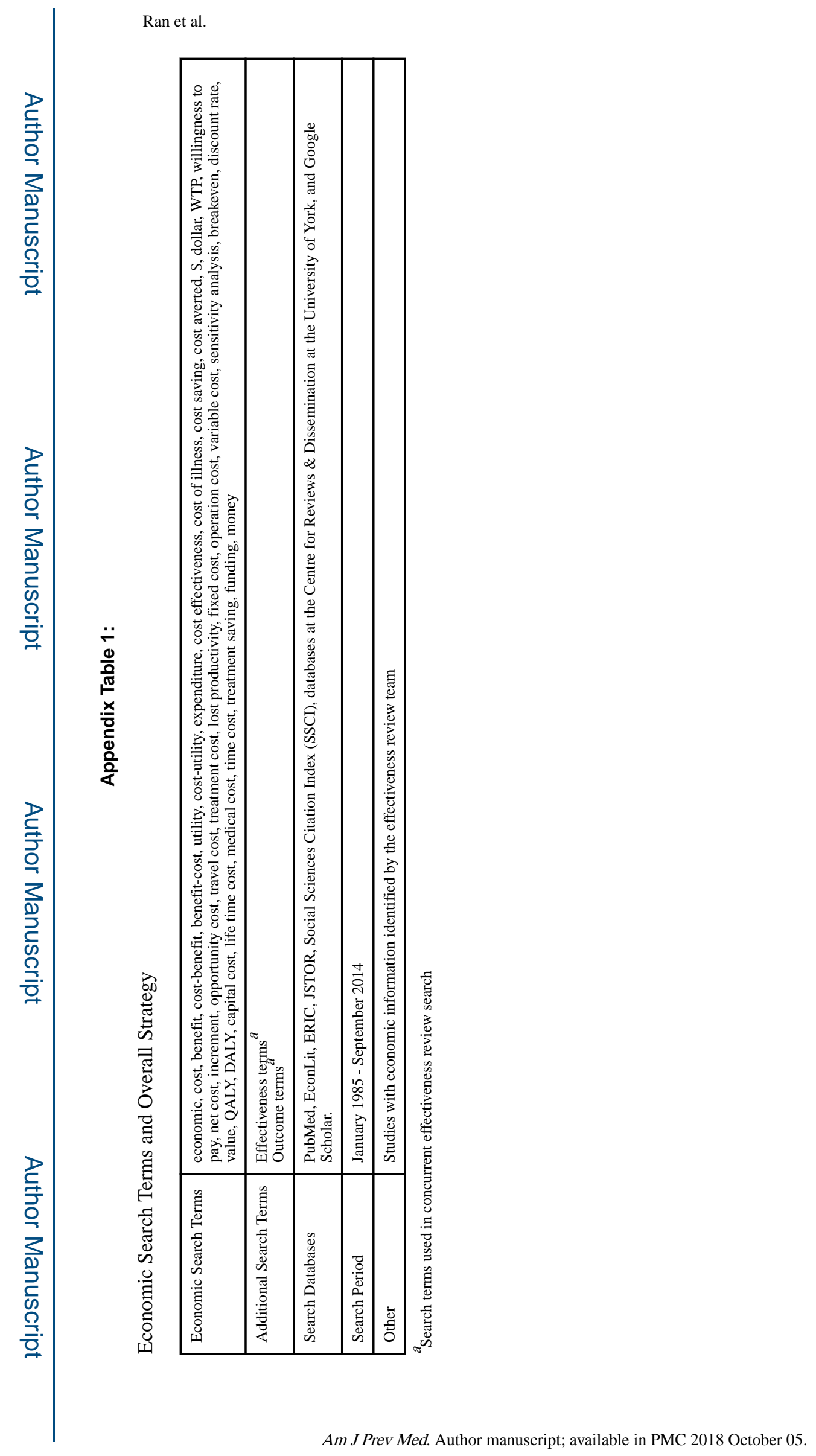

Page 9 


\section{Appendix}




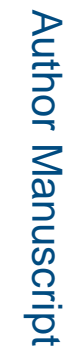

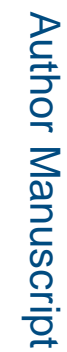

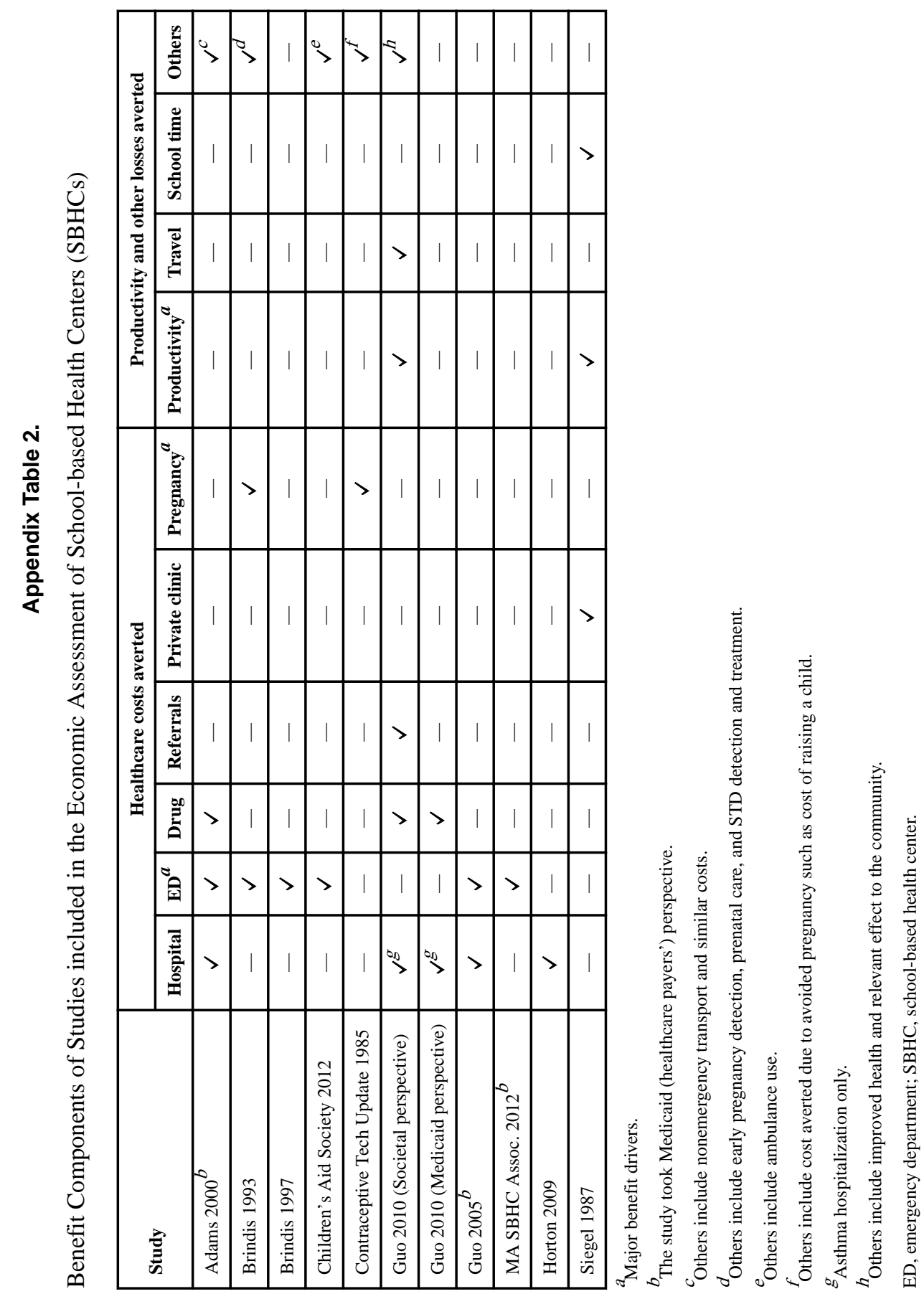

Am J Prev Med. Author manuscript; available in PMC 2018 October 05. 


\section{Appendix}

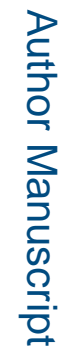

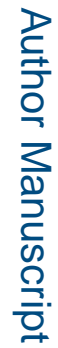

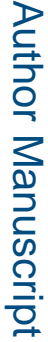




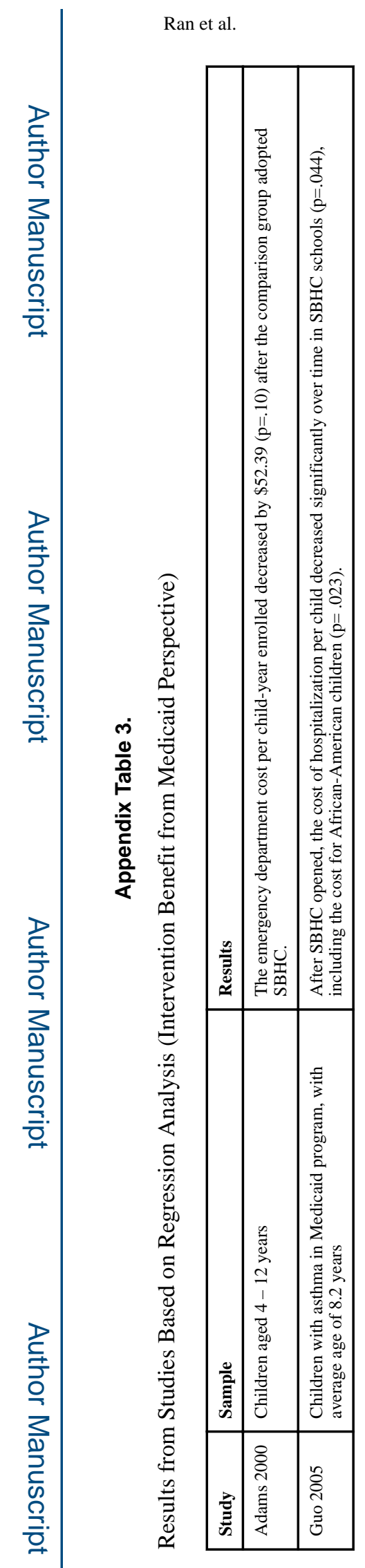

Page 13

Am J Prev Med. Author manuscript; available in PMC 2018 October 05. 


\section{References}

1. Keeton V, Soleimanpour S, Brindis CD. School-based health centers in an era of health care reform: building on history. Curr Probl Pediatr Adolesc Health Care. 2012;42(6):132-156. [PubMed: 22677513]

2. Brindis CD, Sanghvi RV. School-based health clinics: remaining viable in a changing health care delivery system. Annu Rev Public Health. 1997;18:567-587. [PubMed: 9143732]

3. Knopf JA, Finnie RKC, Peng Y, et al. School-based health centers to advance health equity: a Community Guide systematic review. Am J Prev Med. In prep;XXX:XXX.

4. MACPAC. Revisiting emergency department use in Medicaid. Washington, DC: Medicaid and CHIP Payment and Access Commission;2014.

5. Akinbami Lara J. Bailey JEM, Cathy, Zahran Hatice S., King Michael, Johnson Carol A., Liu Xiang. Trends in Asthma Prevalence, Health Care Use, and Mortality in the United States, 20012010. 52012.

6. Carande-Kulis VG, Maciosek Michael V., Briss Peter A., Teutsch Steven M., Zaza Stephanie, Truman Benedict I., Messonnier Mark L. et al. . Methods for systematic reviews of economic evaluations for the Guide to Community Preventive Services. American Journal of Preventive Medicine. 2000;18(1):75-91. [PubMed: 10806980]

7. World Bank, The. Country and lending groups. 2015; data.worldbank.org/about/country-andlending-groups. Accessed June 3, 2015.

8. Bureau of Labor Statistics. Consumer price index. 2015; data.bls.gov/pdq/querytool.jsp?survey=cu. Accessed July 14, 2015.

9. School-based clinics combat teen pregnancy. Contracept Technol Update. 1985;6(4):53-57. [PubMed: 12313867]

10. Adams EK, Johnson V. An elementary school-based health clinic: Can it reduce Medicaid costs? Pediatrics. 2000;105(4):780-788. [PubMed: 10742320]

11. Brindis CD. An Evaluation Study of School-Based Clinics in California: Major Findings, 19861991 San Francisco, CA: University of California, San Francisco; Center for Reproductive Health Policy Research; 1993.

12. Dryfoos J School-based health clinics: a new approach to preventing adolescent pregnancy? Fam Plann Perspect. 1985;17(2):70-75. [PubMed: 3916180]

13. Dryfoos JG. School-based health clinics: three years of experience. Fam Plann Perspect. 1988;20(4):193-200. [PubMed: 3072216]

14. Foch BJ. school-based health centers: a review. International Pediatrics. 1995;10:286-291.

15. Fothergill K, Ballard E. The school-linked health center: a promising model of community-based care for adolescents. J Adolesc Health. 1998;23(1):29-38. [PubMed: 9648020]

16. Fund sCS. School-Based Health Care and the District of Columbia Safety Net. 2004.

17. Guo JJ, Jang R, Keller KN, McCracken AL, Pan W, Cluxton RJ. Impact of school-based health centers on children with asthma. J Adolesc Health. 2005;37(4):266-274. [PubMed: 16182136]

18. Guo JJ, Wade TJ, Pan W, Keller KN. School-based health centers: cost-benefit analysis and impact on health care disparities. Am J Public Health. 2010;100(9):1617-1623. [PubMed: 20634450]

19. Horton JM, Lima-Negron J. School-based health centers: expanding the knowledge and vision. 2009 www.hfwcny.org/Tools/BroadCaster/Upload/Project45/Docs/ School_Based_Health_Centers_July_2009.pdf. Accessed July 15, 2015.

20. Mickinney DH, Peak GL. School-based and School-linked Health Centers, Update 1993. Advocates for Youth 1993.

21. Moore JD, Jr. Healthcare goes to school with kids in Denver County. Mod Healthc. 1998;28(45): 52, 54.

22. Nystrom RJ, Prata A. Planning and sustaining a school-based health center: cost and revenue findings from Oregon. Public Health Rep. 2008;123(6):751-760. [PubMed: 19711656]

23. SBHCs MAo. Making the Cost-Savings Case for School-Based Health Centers SBHCs Avoid Unnecessary Emergency Department Visits: Contribute to Reduction in State Health Care Spending. Massachusetts Association of SBHCs;2012. 
24. Schlitt JJ, Juszczak LJ, Eichner NH. Current status of state policies that support school-based health centers. Public Health Rep. 2008;123(6):731-738. [PubMed: 19711654]

25. Siegel LP, Krieble TA. Evaluation of school-based, high school health services. J Sch Health. 1987;57(8):323-325. [PubMed: 3121915]

26. Silberberg M, Cantor JC. Making the Case for School-Based Health: Where Do We Stand? Journal of Health Politics, Policy and Law. 2008;33(1):3-37.

27. Society CsA. School Based Health Centers. Childeren's Aid Society;2012.

28. Tereszkiewicz LaCB. School-Based Clinics Offer Health Care to Teens. Youth Law News 1986. 


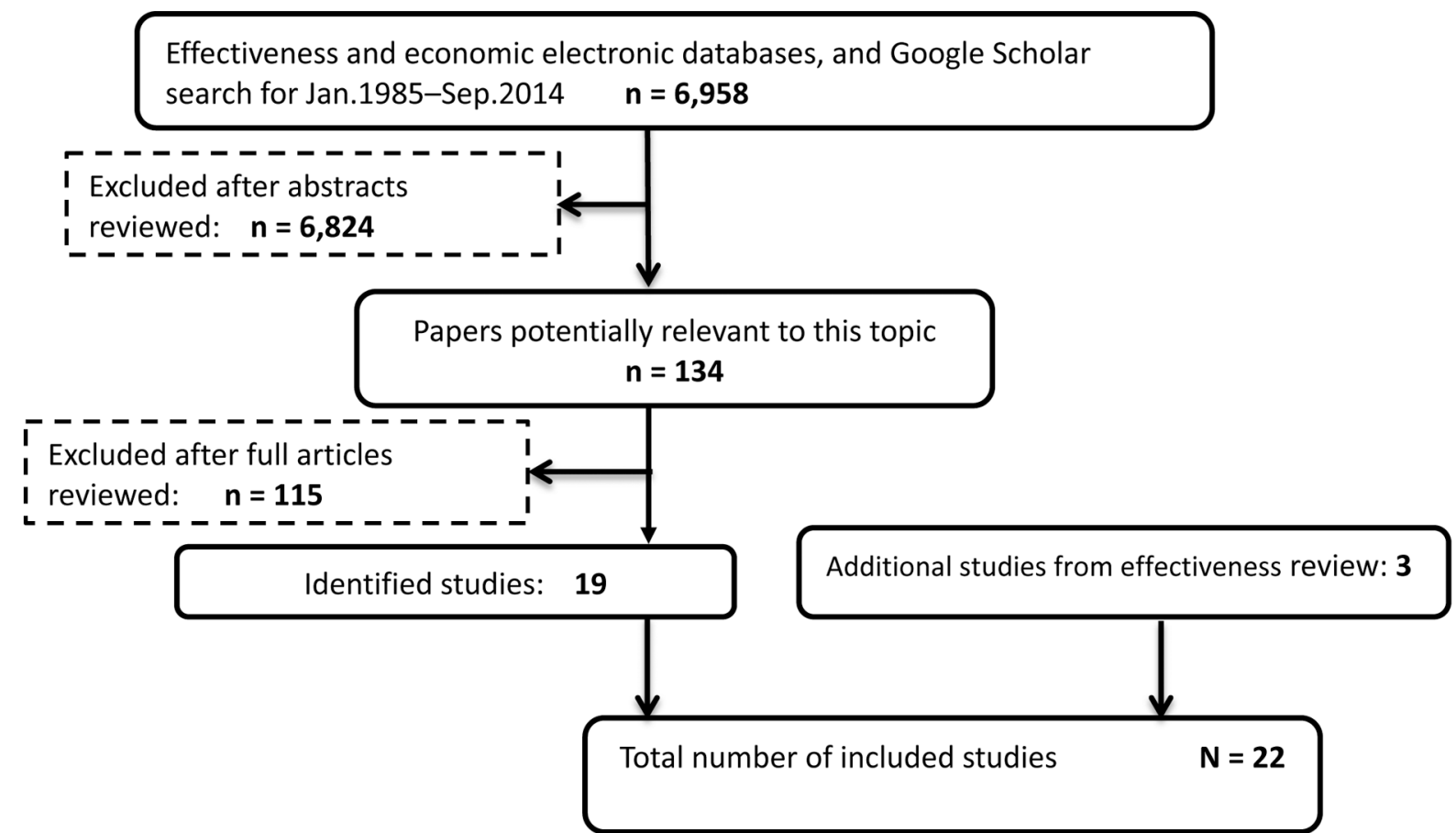

Figure 1.

Flowchart showing path from initial search list to included studies. 


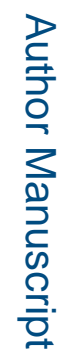

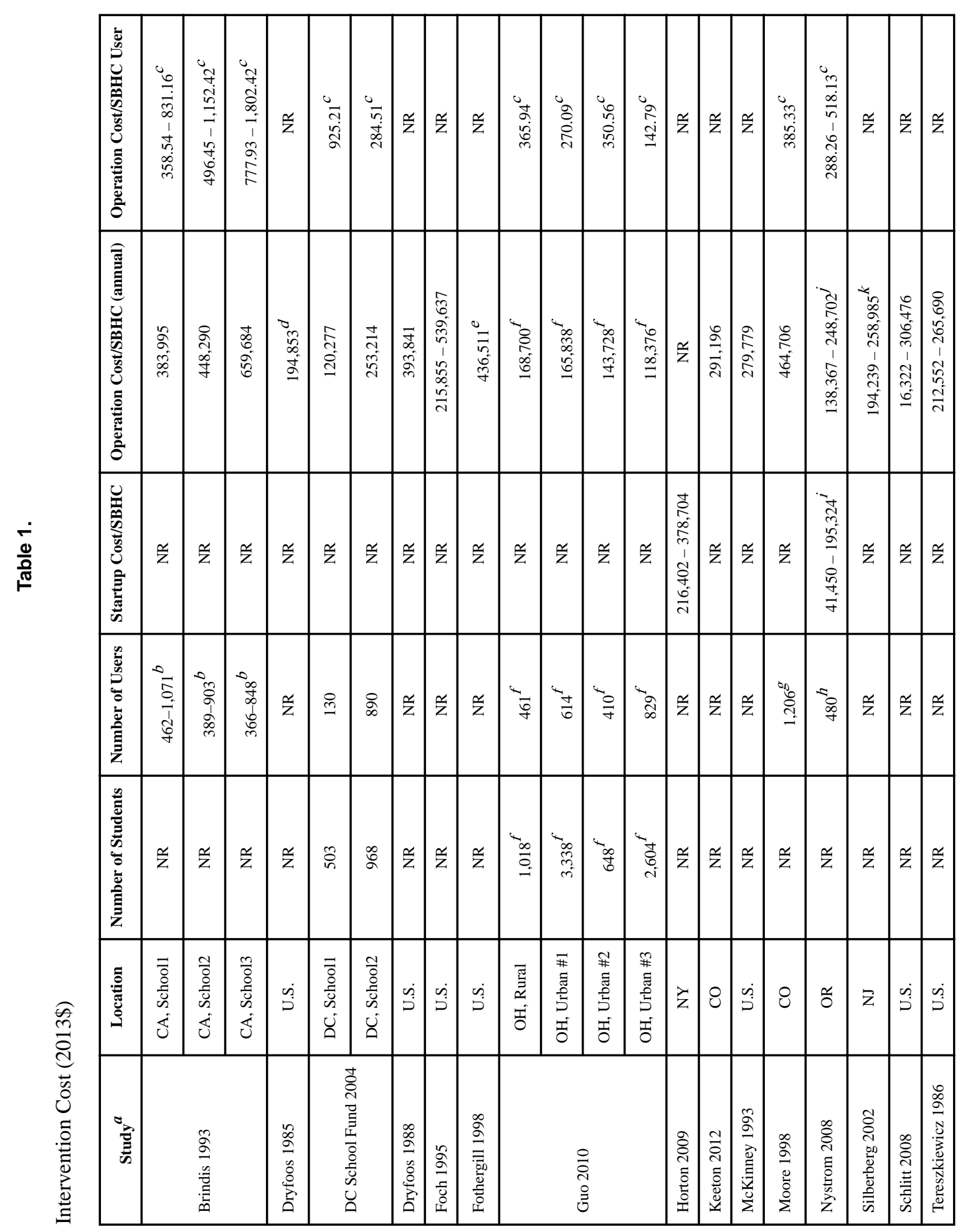

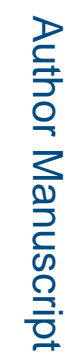

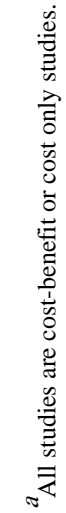

Am J Prev Med. Author manuscript; available in PMC 2018 October 05. 


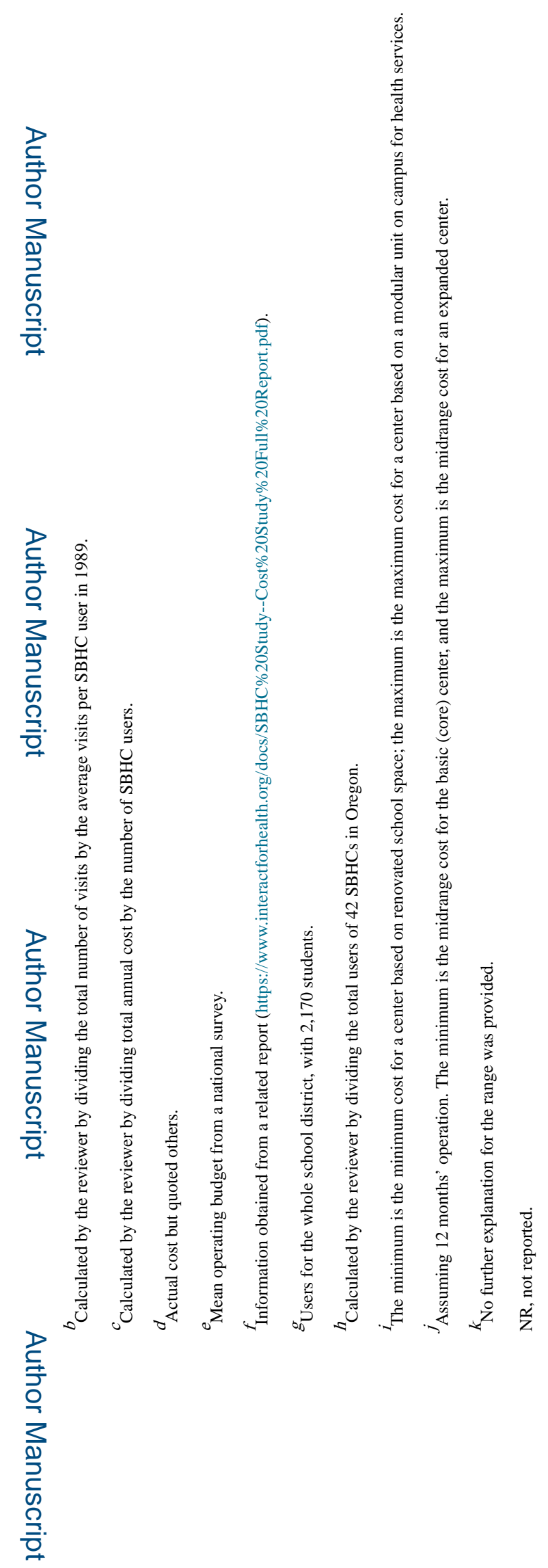

Am J Prev Med. Author manuscript; available in PMC 2018 October 05. 
Table 2.

Intervention Benefit: From Societal, Healthcare Payers', and Patients’ Perspectives (2013\$)

\begin{tabular}{|c|c|c|c|c|}
\hline \multicolumn{5}{|l|}{ From Societal Perspective } \\
\hline Study & Location & $\begin{array}{c}\text { Major Benefit Driver(s) (\# } \\
\text { Components) }\end{array}$ & Annual $^{a}$ Benefit /SBHC & Annual Benefit /SBHC user \\
\hline \multirow{3}{*}{ Brindis 1993} & CA, School1 & Pregnancy (3) & 912,878 & $852.36-1,975.93^{b}$ \\
\hline & CA, School2 & Pregnancy (3) & 769,524 & $852.19-1,978.21^{b}$ \\
\hline & CA, School3 & Pregnancy (3) & 843,677 & $994.90-2,305.13^{b}$ \\
\hline \multirow{4}{*}{ Guo 2010} & $\mathrm{OH}$ & Productivity (6) & 361,581 & $784.34^{b}$ \\
\hline & $\mathrm{OH}$ & Productivity (6) & 361,581 & $588.89^{b}$ \\
\hline & $\mathrm{OH}$ & Productivity (6) & 361,581 & $881.90^{b}$ \\
\hline & $\mathrm{OH}$ & Productivity (6) & 361,581 & $436.17^{b}$ \\
\hline Horton 2009 & NY & None (1) & $15,028^{c}$ & NR \\
\hline \multicolumn{5}{|c|}{ From Medicaid (healthcare payers') Perspective } \\
\hline Study & Location & $\begin{array}{c}\text { Major Benefit Driver(s) (\# } \\
\text { Components) }\end{array}$ & Net savings /visit & Net savings/ SBHC user \\
\hline \multicolumn{5}{|l|}{ SBHC users without asthma } \\
\hline Adams 2000 & GA & $\mathrm{ED}(4)$ & NR & $404^{d}$ \\
\hline MA SBHC Assoc. $2012^{e}$ & MA & $\mathrm{ED}(1)$ & $203^{f}$ & NR \\
\hline \multicolumn{5}{|l|}{ SBHC users with asthma } \\
\hline Adams 2000 & GA & $\mathrm{ED}(4)$ & NR & 1,166 \\
\hline Guo 2005 & $\mathrm{OH}$ & $\mathrm{ED}(2)$ & $969^{g}$ & NR \\
\hline MA SBHC Assoc. $2012^{e}$ & MA & $\mathrm{ED}(1)$ & $604^{f}$ & NR \\
\hline \multicolumn{5}{|l|}{ Users in general } \\
\hline Guo 2010 & $\mathrm{OH}$ & Drugs (2) & 30 & 46 \\
\hline \multicolumn{5}{|l|}{ From Patients' Perspective } \\
\hline Study & Location & $\begin{array}{c}\text { Major Benefit Driver(s) (\# } \\
\text { Components) }\end{array}$ & Savings /visit & Savings / SBHC user \\
\hline $\begin{array}{c}\text { Contraceptive Technology } \\
\text { Update } 1985\end{array}$ & MS & Pregnancy (1) & NR & $23,592^{h}$ \\
\hline Siegel 1987 & $\mathrm{DE}$ & Productivity (3) & $90^{i}$ & NR \\
\hline \multicolumn{5}{|l|}{ From Other Perspectives } \\
\hline Study & Location & $\begin{array}{c}\text { Major Benefit Driver(s) (\# } \\
\text { Components) }\end{array}$ & Savings /visit & Perspective \\
\hline Brindis 1997 & $\mathrm{CA}$ & $\mathrm{ED}(1)$ & $162-262$ & Unidentified \\
\hline Children's Aid Society 2012 & NY & $\mathrm{ED}(2)$ & $1,077^{j}$ & Taxpayer \\
\hline
\end{tabular}

A Annual benefit was calculated by the reviewer by dividing the total benefit over three years by three for Guo 2010; while Brindis 1993 implied that the benefit was yearly. 
${ }^{b}$ Calculated by the reviewer by dividing the total annual benefit by the number of users in Table 1.

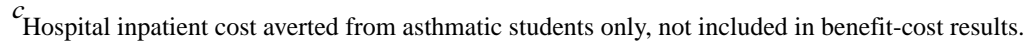

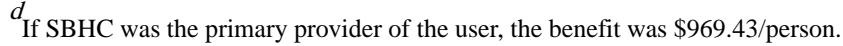

${ }^{e}$ Assuming $50 \%$ of the ED use was avoided because of SBHC usage.

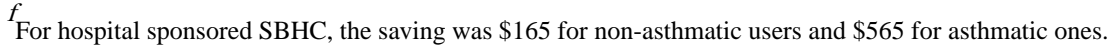

$g_{\text {Hospitalization savings only, the saving in ED use was not significant. }}$

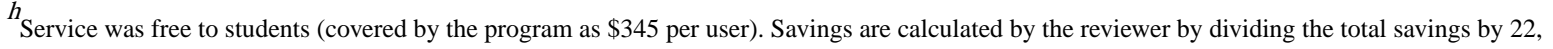
since total savings were from not raising a child to age 22 .

${ }^{i}$ Service was free to enrolled students (covered by the Division of Public Health as $\$ 43.86$ per visit). Cost was compared with that from a private clinic.

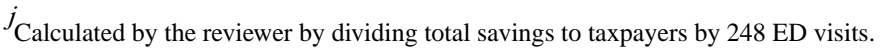

Comps, components; DID, Difference-in-Differences; ED, emergency department; NR, Not reported; SBHC, school-based health centers. 
Table 3

Benefit-Cost Ratio and Net Benefit

\begin{tabular}{|l|l|c|c|c|c|}
\hline Study & Location & Number of students & Number of users & Benefit-Cost ratio & $\begin{array}{l}\text { Net benefit } \\
(\mathbf{2 0 1 3} \$ \mathbf{~}\end{array}$ \\
\hline \multirow{3}{*}{ Brindis 1993 } & CA, School1 & NR & $462-1,071$ & $1.38: 1$ & $\$ 253,195$ \\
\cline { 2 - 6 } & CA, School2 & NR & $389-903$ & $2.00: 1$ & $\$ 385,529$ \\
\cline { 2 - 6 } & CA, School3 & NR & $366-848$ & $1.88: 1$ & $\$ 395,387$ \\
\hline \multirow{3}{*}{ Guo 2010 } & OH, Rural & 1,018 & 461 & $2.14: 1^{a}$ & $\$ 192,880$ \\
\cline { 2 - 6 } & OH, Urban\#1 & 3,338 & 614 & $2.18: 1^{a}$ & $\$ 195,742$ \\
\cline { 2 - 6 } & OH, Urban\#2 & 648 & 410 & $2.52: 1^{a}$ & $\$ 217,852$ \\
\cline { 2 - 6 } & OH, Urban\#3 & 2,604 & 829 & $3.05: 1^{a}$ & $\$ 243,204$ \\
\hline
\end{tabular}

${ }^{a}$ Calculated by the reviewer by dividing annual benefit by annual cost.

NR, not reported. 


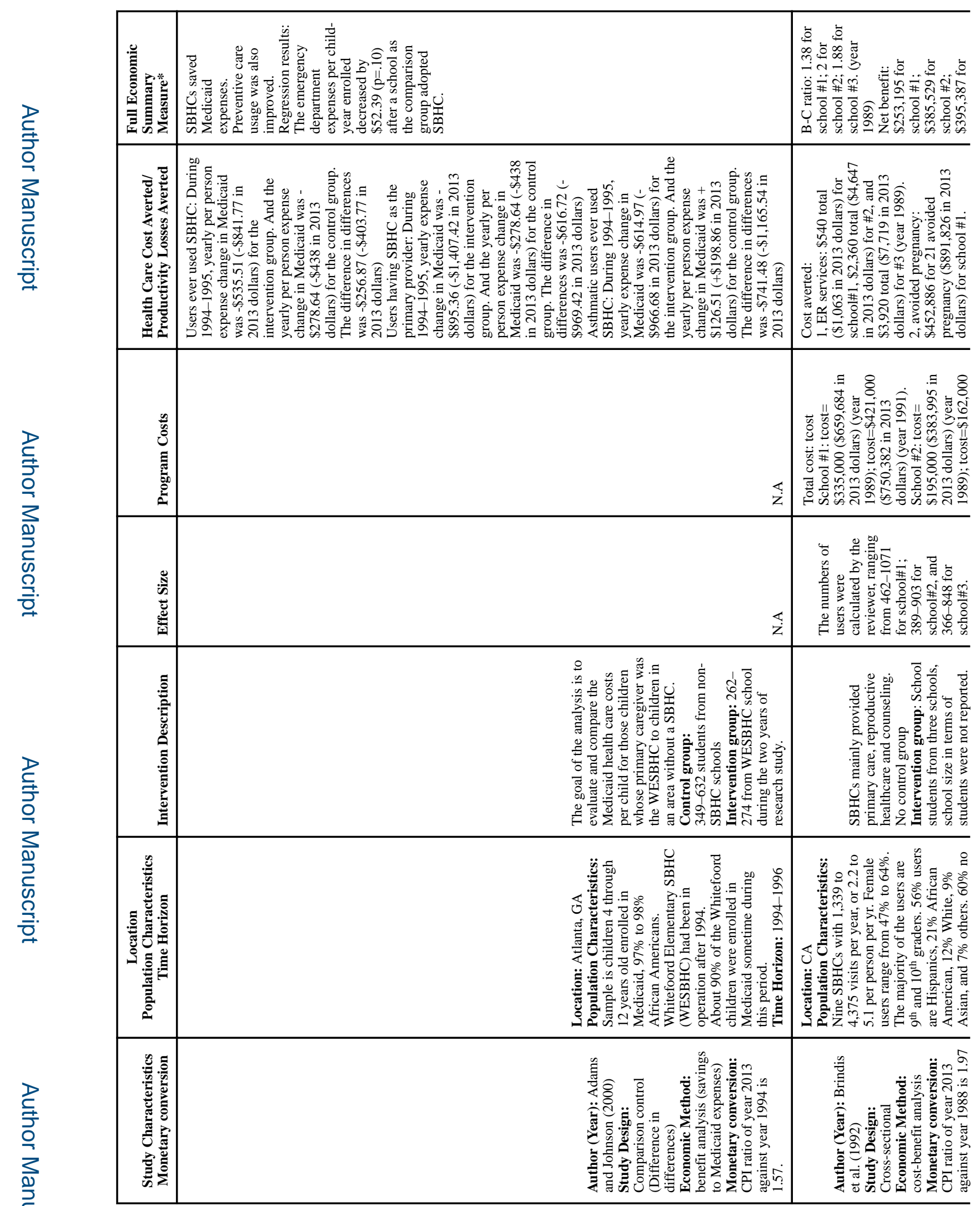

Am J Prev Med. Author manuscript; available in PMC 2018 October 05. 


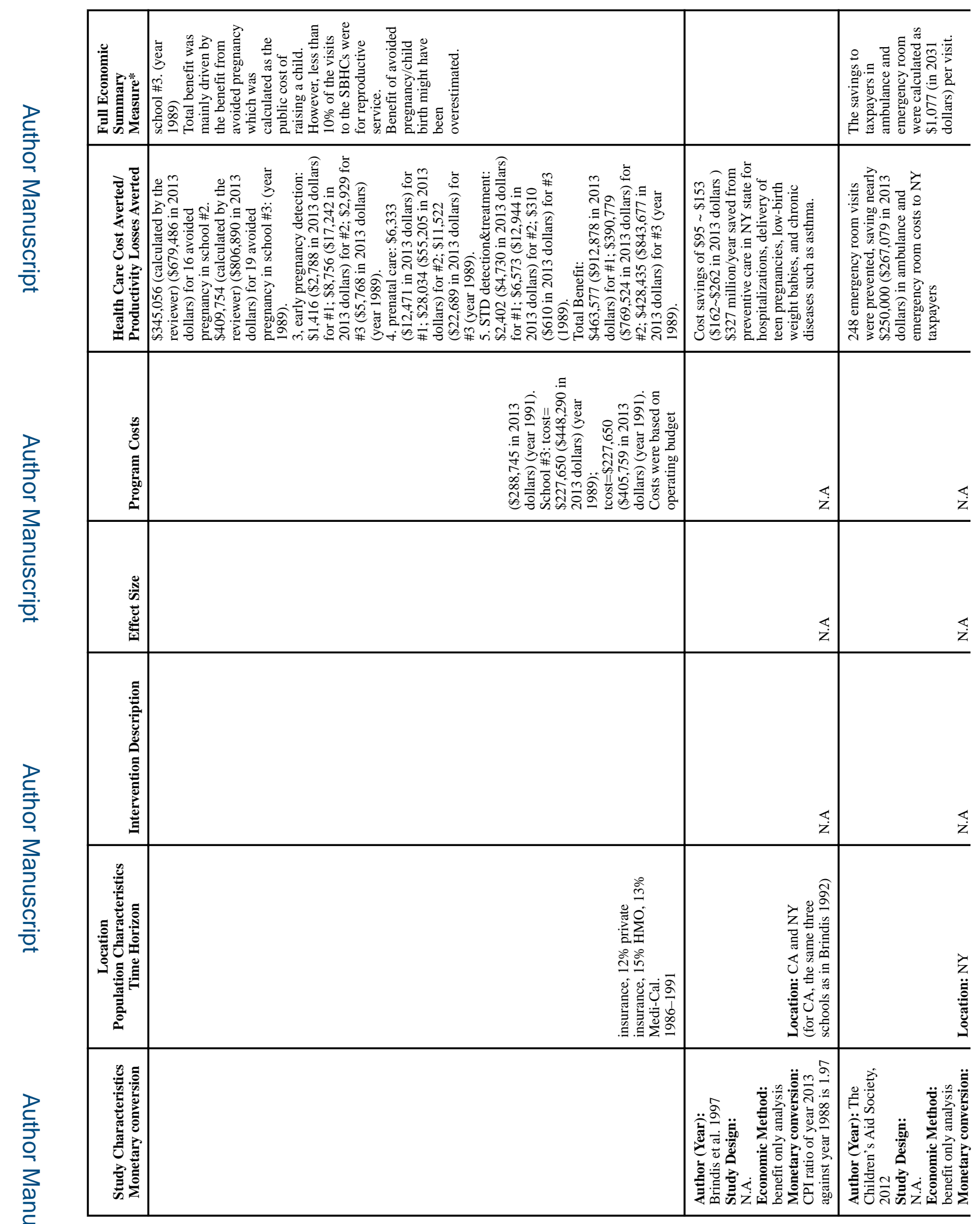

Am J Prev Med. Author manuscript; available in PMC 2018 October 05. 


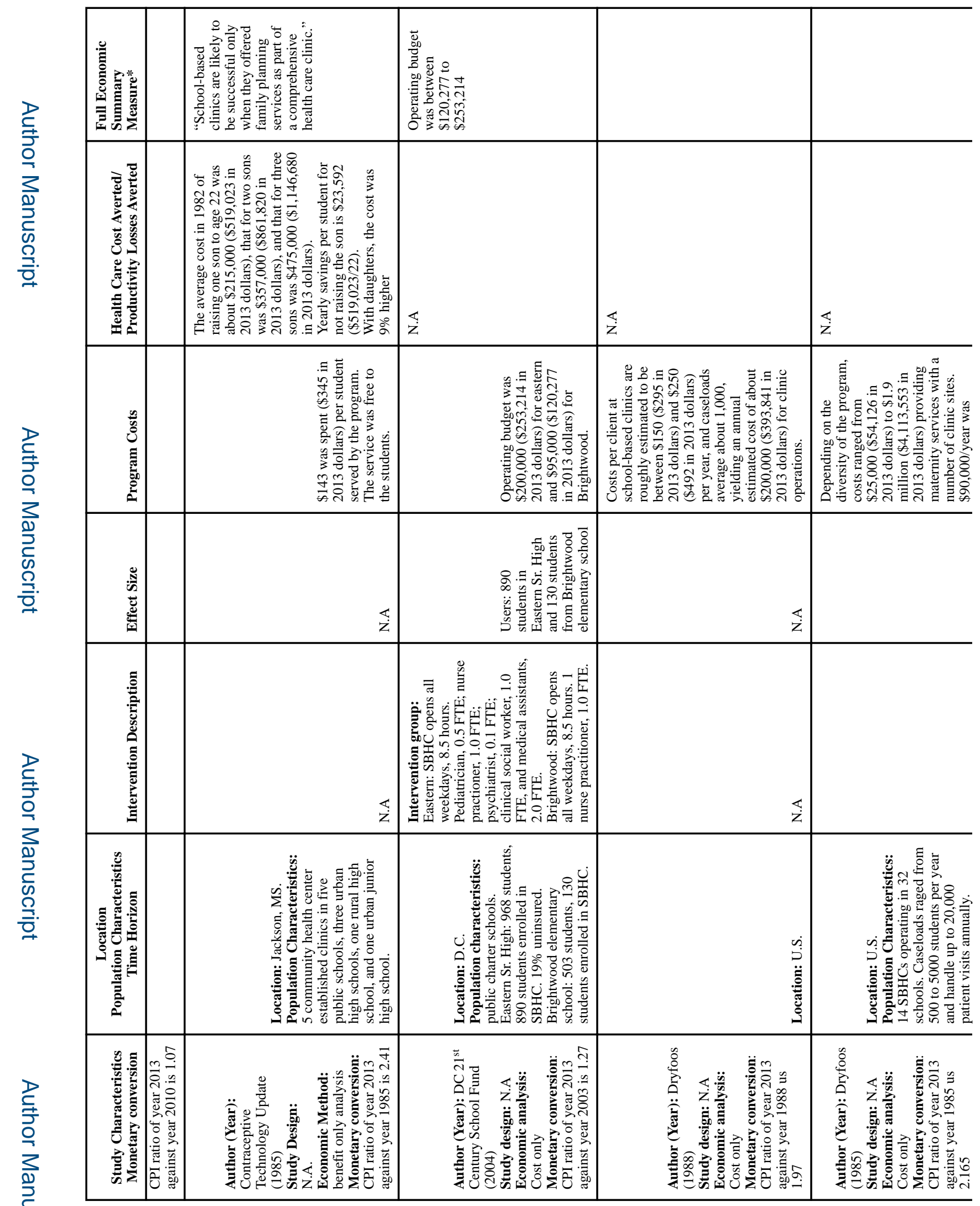

Am J Prev Med. Author manuscript; available in PMC 2018 October 05. 


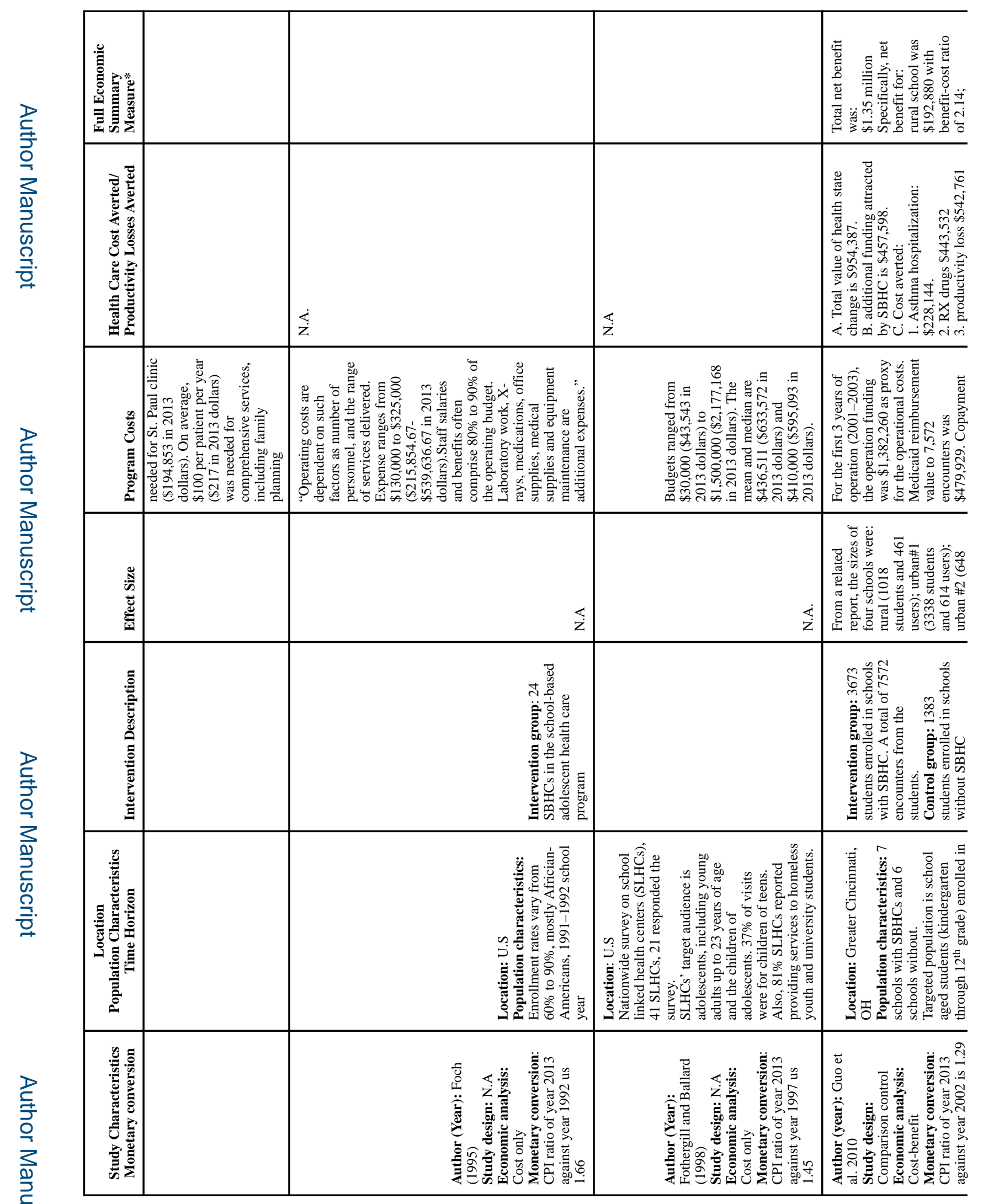

Am J Prev Med. Author manuscript; available in PMC 2018 October 05. 


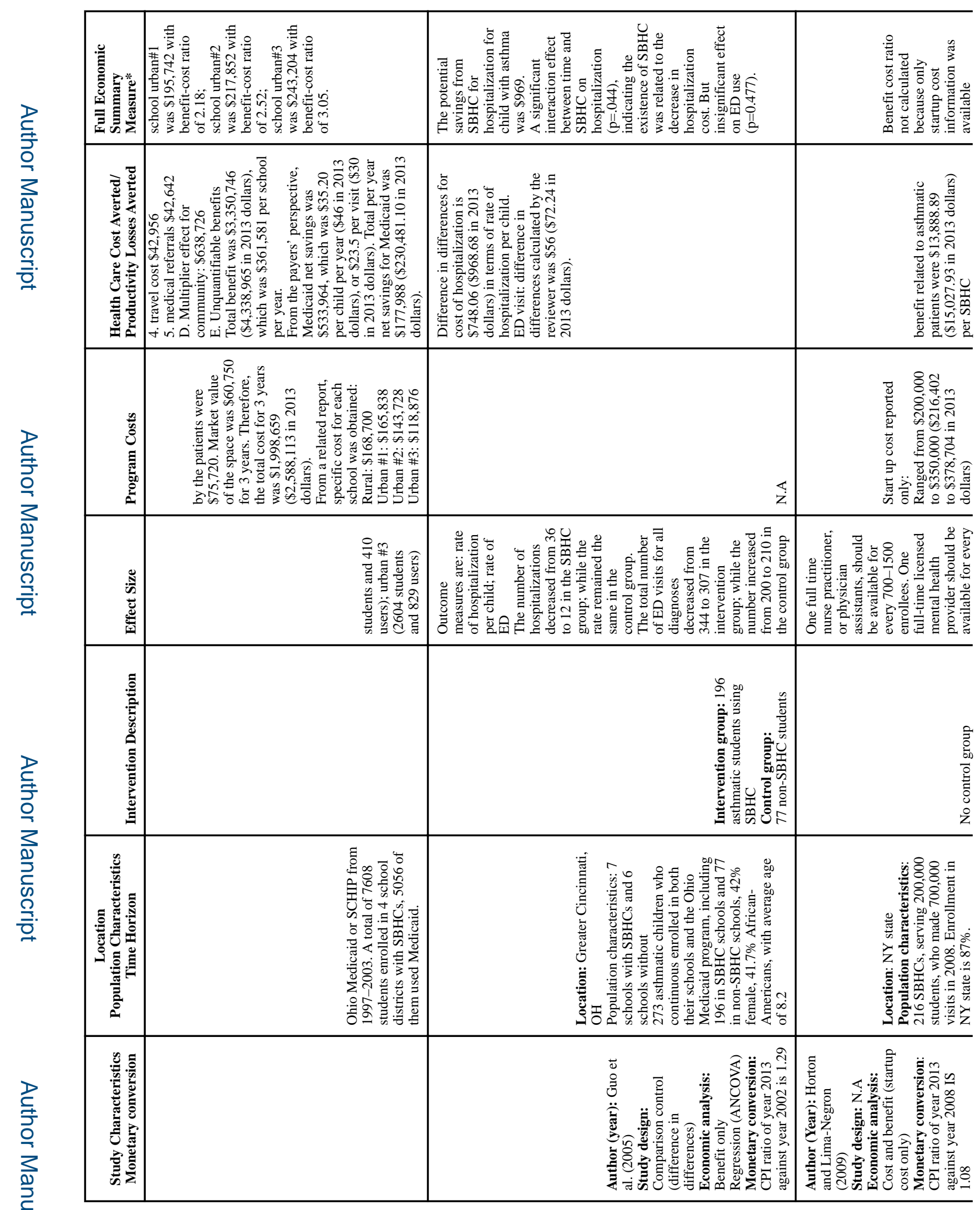

Am J Prev Med. Author manuscript; available in PMC 2018 October 05. 


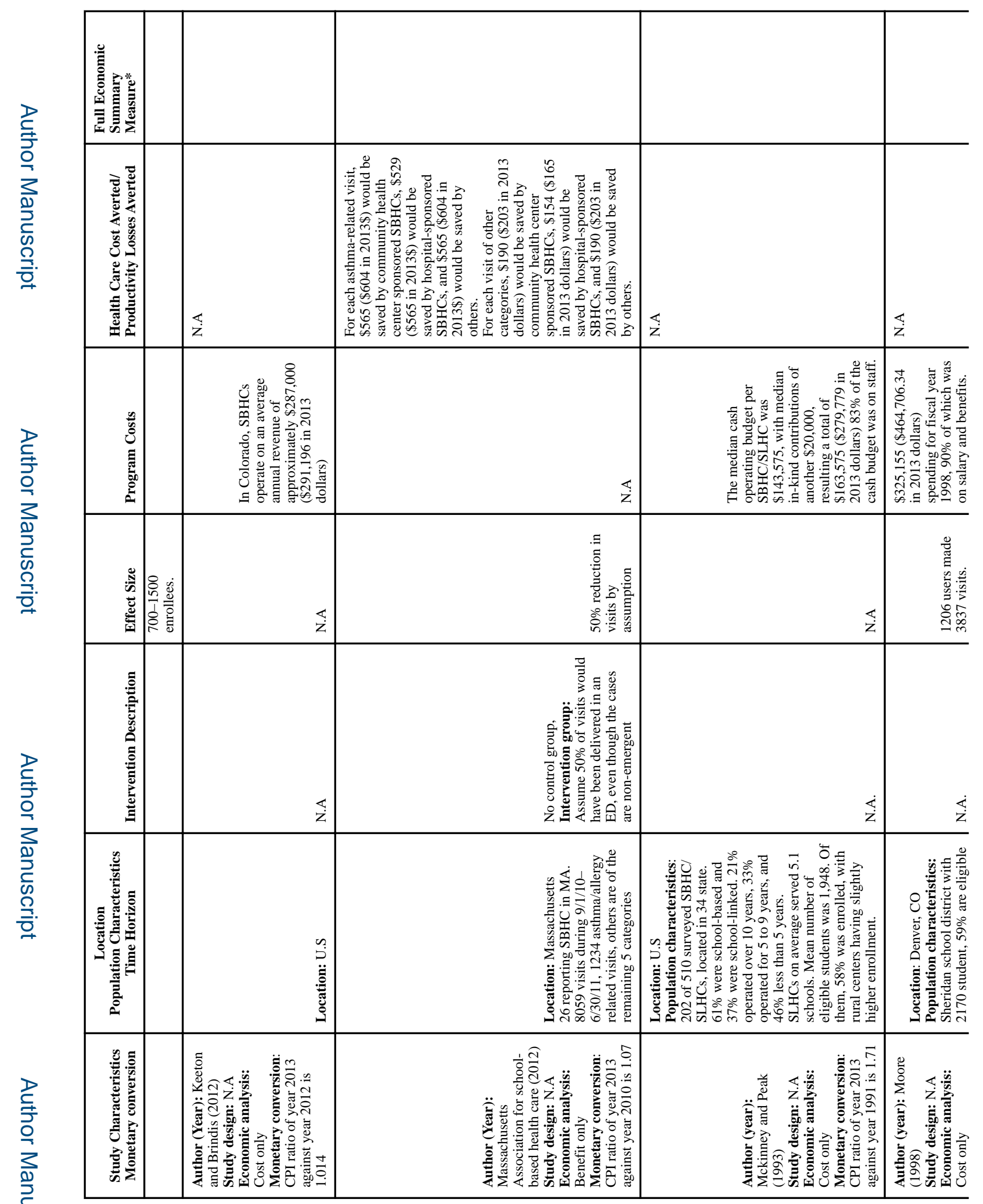

Am J Prev Med. Author manuscript; available in PMC 2018 October 05. 


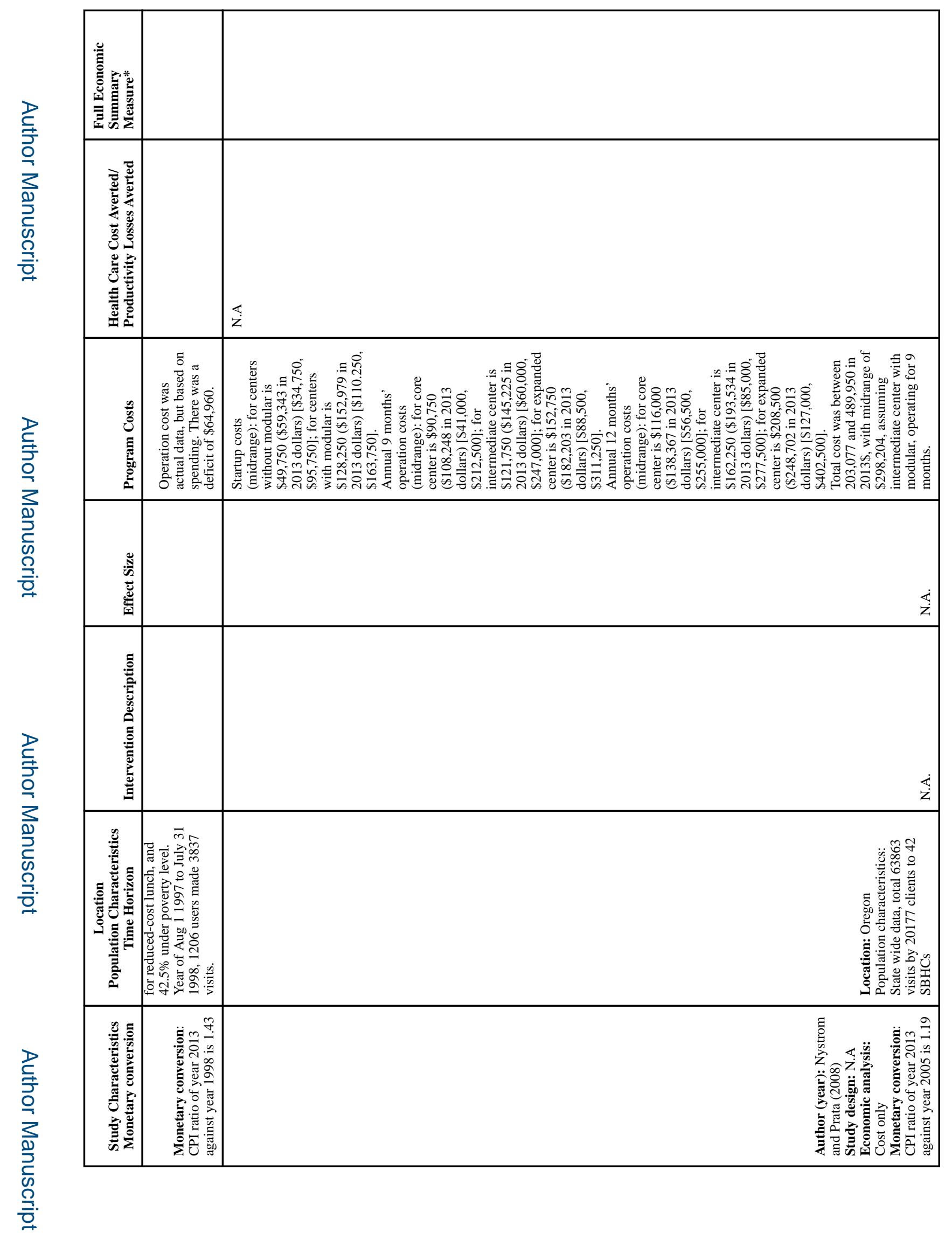

Am J Prev Med. Author manuscript; available in PMC 2018 October 05. 


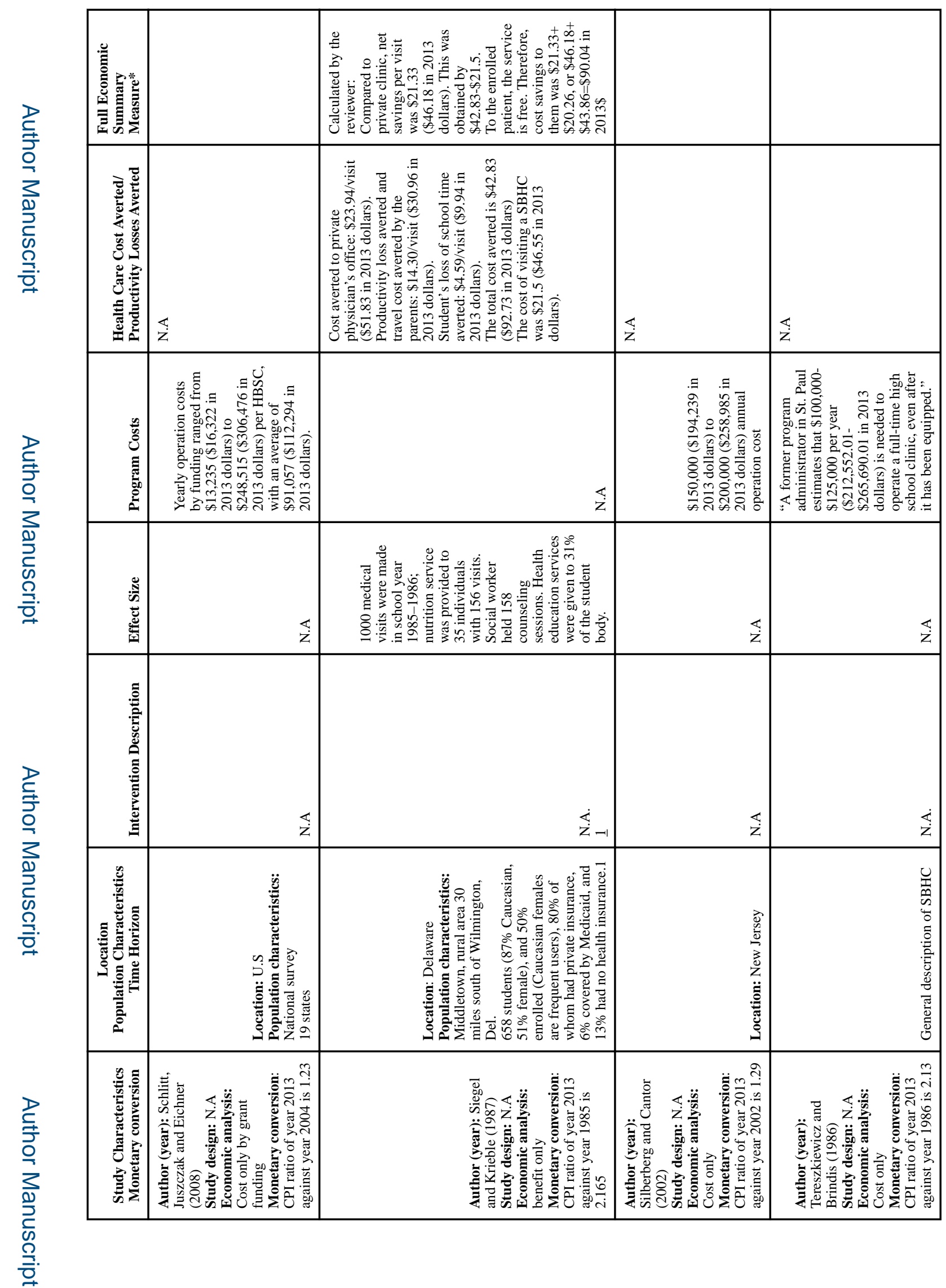

Am J Prev Med. Author manuscript; available in PMC 2018 October 05. 